\title{
AS FERRAMENTAS DA CONTABILIDADE GERENCIAL APLICADAS AOS ESTOQUES DE MATERIAIS PARA TOMADA DE DECISÕES NAS EMPRESAS COMERCIAIS DE PEQUENO PORTE EM MEIO CRISE ECONÔMICA DA PANDEMIA COVID-19
}

\section{ARTIGO ORIGINAL}

FONSECA, Douglas Cavalcante da1, PRADO, Emyle Rebeca de Souza², MOUZINHO, Rebeca Cristina Oliveira ${ }^{3}$, MORAES, Victor Hugo Silva $\mathrm{de}^{4}$, ROBERTO, José Carlos Alves ${ }^{5}$, SERRA, Meg Rocha da Cunha ${ }^{6}$, LOPES, Nelânia Ferreira $^{7}$

FONSECA, Douglas Cavalcante da. Et al. As ferramentas da contabilidade gerencial aplicadas aos estoques de materiais para tomada de decisões nas empresas comerciais de pequeno porte em meio crise econômica da pandemia Covid-19. Revista Científica Multidisciplinar Núcleo do Conhecimento. Ano. 06, Ed. 11, Vol. 09, pp. 152-168. Novembro 2021. ISSN: 2448-0959, Link de acesso: https://www.nucleodoconhecimento.com.br/contabilidade/contabilidade-gerencialaplicadas, DOI: 10.32749/nucleodoconhecimento.com.br/contabilidade/contabilidade-gerencialaplicadas

\footnotetext{
${ }^{1}$ Graduando do curso de Contabilidade.

${ }^{2}$ Graduando do curso de Contabilidade.

${ }^{3}$ Graduando do curso de Contabilidade.

${ }^{4}$ Graduando do curso de Contabilidade.

${ }^{5}$ Orientador. Mestre em Engenharia de produção. Especialista Logística empresarial. Graduado em Administração com Ênfase em Marketing.

${ }^{6}$ Orientadora. Mestra em Engenharia de Processos Industriais pela UFPA , Especialista em Controladoria e Auditoria Contábil pelo Ciesa, Graduada em Ciências Contábeis pelo Centro Universitário do Norte. Graduada em Ciências Econômicas pelo Centro Universitário do Norte.

${ }^{7}$ Orientadora. Especialista em Auditoria Contábil, Financeira e Tributaria e Graduada em Ciências Contábeis.
}

RC: 101629

Disponível em:

https://www.nucleodoconhecimento.com.br/contabilidade/contabilidade-gerencialaplicadas 


\section{RESUMO}

Este artigo propõe-se apresentar as ferramentas da contabilidade gerencial nos processos operacionais para tomada de decisão nas empresas, conceituando que para decisões bem-sucedidas é necessário que se utilize ferramentas adequadas que compõe a contabilidade gerencial, cujo direcionamento deste estudo, enfatiza o gerenciamento para estoques de materiais nas empresas comerciais de pequeno porte em meio a crises econômica da pandemia covid-19. As pesquisas bibliográficas apontam que o estoque é uma área bastante significativa, devendo estar em constante rotatividade de materiais, por ser a principal fonte de capital de giro das empresas. Através desse questionamento surge a pergunta problema do tema abordado: Quais ferramentas da contabilidade gerencial podem trazer resultados satisfatórios no gerenciamento dos estoques dessas empresas? objetivo geral consiste em apresentar as ferramentas adequadas da contabilidade gerencial para tomadas de decisões no gerenciamento dos estoques de materiais das empresas comerciais de pequeno porte em momentos de crise econômica. Este estudo foi realizado por meio de procedimentos metodológicos utilizando pesquisa qualitativa de natureza aplicada e por meios bibliográficos. Como resultado, o estudo apresenta as ferramentas da contabilidade aplicadas ao estoque para tomada de decisão das empresas comerciais de pequeno porte e que passam a ser importantes instrumentos fundamentais de apoio à gestão em momentos de crise. Portanto, conclui-se que 0 estudo atinge seus objetivos na medida em que apresenta as ferramentas e a atuação da contabilidade gerencial na gestão empresarial, proporcionando ferramentas operacionais e gerenciais que produzam resultados financeiros na tomada de decisão.

Palavras-chave: Contabilidade gerencial, Empresa de pequeno porte, Crise econômica. 


\section{INTRODUÇÃO}

O propósito deste artigo é apresentar ferramentas da contabilidade gerencial aplicadas aos estoques de materiais para tomada de decisão nas empresas comerciais de pequeno porte em meio à crise econômica da pandemia covid-19. A continuidade e o progresso de uma empresa sujeitam-se à produção de seus bens e serviços e o custo do produto, definindo-se de acordo com o emprego de um bom sistema produtivo. A falta de controle, planejamento e programação referente às informações importantes para tomadas de decisões na empresa, podem levar à diminuição do lucro de uma empresa. Porém, a existência de imprevistos impossibilita a elaboração de planos que tragam uma saída para determinado problema.

A pandemia da covid-19 trouxe consequências para as empresas de diferentes segmentos de mercado, onde tiveram dificuldades de lidar com a situação, que se tornava agravante a cada dia. Um dos segmentos mais afetados foram os empreendimentos do mercado industrial, fazendo com que as empresas ficassem com estoques de matérias primas insuficiente para atender o processo produtivo e consequentemente afetar a cadeia de consumidores, trazendo instabilidade financeira e econômica.

Muitas empresas não estavam preparadas para este cenário econômico perante a crise, algumas decisões tiveram que ser tomadas para que não afetasse diretamente a vida financeira e econômica das empresas para se manterem no mercado. Contudo, busca-se pesquisar uma área bastante afetada, os estoques de mercadorias nas empresas de pequeno porte do ramo comercial. Com isso, levantou-se a seguinte pergunta que auxiliará o tema abordado: Quais ferramentas da contabilidade gerencial podem trazer resultados satisfatórios para essas empresas? 
Nesse contexto, os objetivos para o desenvolvimento deste trabalho consistem em apresentar as ferramentas adequadas da contabilidade gerencial para tomadas de decisões no gerenciamento dos estoques de materiais das empresas comerciais de pequeno porte em momentos de crise econômica, mostrando que um controle de estoques eficiente é essencial para manter as empresas no mercado.

A contabilidade gerencial que normalmente já se encontra presente no dia a dia das empresas, auxiliando gestores na tomada de decisões frente às problemáticas habituais do desempenho de suas atividades, que tenham impactos positivos a curto, médio e longo prazo, mantendo assim um bom funcionamento e crescimento do negócio, tem ampla possibilidades de auxiliar na elaboração de uma estratégia para transpor a crise.

\section{FUNDAMENTAÇÃO TEÓRICA}

Segundo Menezes et al. (2019), a fundamentação teórica é o acesso à base de informações que dará conhecimento, a saber: dissertações, teses, jornais, dicionários e áreas que especificam documentos históricos. De fato, todo bom artigo tem sua pesquisa, seja ela fundamentada ou pesquisada, de modo que tenha uma revisão bibliográfica.

\subsection{CONCEITO DE CONTABILIDADE GERENCIAL}

Para Atrill e Mclaney (2014), a contabilidade gerencial trata do conjunto de informações gerais da empresa. A gestão de cada organização deve ser relativa com a alocação de recursos econômicos escassos. Para garantir uma boa gestão, ela deve ser feita de uma maneira eficiente para que as informações econômicas possam fundamentar as decisões.

De acordo com ludícibus (2015), a contabilidade ensina a teoria, métodos de registro, cálculos e movimentação financeira de cada firma ou empresa. O objetivo é demonstrar o financeiro e promover as informações úteis para a tomada de decisão.

RC: 101629

Disponível em:

https://www.nucleodoconhecimento.com.br/contabilidade/contabilidade-gerencialaplicadas 
De acordo com ludícibus (2015), a contabilidade ensina a teoria, métodos de registro, cálculos e movimentação financeira de cada firma ou empresa. O objetivo é demonstrar o financeiro da empresa e promover as informações úteis para a tomada de decisão.

Conforme Garrison (2013), a contabilidade gerencial com relação às atividades, como: controle, planejamento e tomada de decisões, envolve objetivos específicos a serem alcançados, porém, o controle envolve garantir a execução das ações de forma adequada e modifica à medida que as circunstâncias mudam.

Para Atrill e Mclaney (2014), a contabilidade gerencial promove certas vantagens por auxiliar as empresas a identificar suas informações econômicas relevantes, registar estas de maneira sistemática, analisar e entender as informações coletadas, apresentando-as de forma clara para o gestor.

\subsection{CRISE ECONÔMICA: PANDEMIA COVID-19}

De acordo com Dorion (2021), a pandemia desestruturou a economia brasileira, principalmente as Micro e Pequenas Empresas (MPEs) que passaram a viver em situações problemáticas com acontecimentos inesperados e com a incerteza do que poderia vir a acontecer futuramente.

Para Lira e Almeida (2020), a pandemia do coronavírus afetou substancialmente o mercado financeiro e interferiu decisivamente nos empreendimentos do mundo inteiro, alterando resultados e causando impactos negativos em todos os setores da economia. Observou-se, com mais evidência, uma insegurança em todos os segmentos sociais e econômicos, que rapidamente se transformou em uma crise nas economias em nível nacional e mundial. As restrições impostas pelas autoridades na reabertura do comércio também alteraram o andamento do trabalho, pois houve a redução do número de funcionários e de pessoas no local, bem como a obrigação do distanciamento social e do uso de máscaras durante todo o horário de expediente (TAGLIANI, 2020).

RC: 101629

Disponível em:

https://www.nucleodoconhecimento.com.br/contabilidade/contabilidade-gerencialaplicadas 
Durante a pandemia, o Governo Federal não possuía um plano de ações devidamente organizado e articulado para amenizar os efeitos da pandemia sobre as atividades econômicas ou para diminuir os impactos financeiros (MATTEI e HEINEN, 2020).

\subsection{EMPRESAS COMERCIAIS DE PEQUENO PORTE}

Segundo a Lei Complementar $n^{\circ}$ 123/2006, art 3: a receita bruta superior a $R \$$ $360.000,00$ (trezentos e sessenta mil reais) e igual ou inferior a $R \$ 4.800 .000,00$ (quatro milhões e oitocentos mil reais) classifica uma empresa de pequeno porte.

As pequenas empresas sempre tiveram uma significativa participação e importância na economia no país. Segundo o governo federal, em uma publicação realizada em 2020, destacando o papel das micro e pequenas empresas, indicou que tais empresas representam $99 \%$ dos negócios brasileiros, respondem por $30 \%$ de tudo que é produzido no país e são responsáveis por $55 \%$ dos empregos gerados no Brasil. Em citação a um artigo publicado pelo SEBRAE, o presidente do SEBRAE, Luiz Barreto diz: "cerca de 9 milhões de micro e pequenas empresas no país representam 27\% do PIB (Produto Interno Bruto), um resultado que vem crescendo nos últimos anos". Uma pesquisa da Boa Vista (2019), informa que as micro e pequenas empresas são as mais prováveis a investir no Brasil.

Segundo o SEBRAE (2014), se utiliza o número de pessoas empregadas como critério de classificação do porte das empresas:

- Microempresa: até 9 pessoas empregadas para serviços e, em comércio, até 19 pessoas empregadas para a indústria;

- Pequena Empresa: de 10 a 49 pessoas empregadas para serviços e, em comércio, de 20 a 99 pessoas empregadas para indústria;

- Média Empresa: de 50 a 99 pessoas empregadas para serviços e, em comércio, de 100 a 499 pessoas empregadas para indústria;

RC: 101629

Disponível em:

https://www.nucleodoconhecimento.com.br/contabilidade/contabilidade-gerencialaplicadas 
- Grande Empresa: acima de 100 pessoas empregadas para serviços e, em comércio, acima de 500 pessoas empregadas para indústria.

\subsection{CONCEITO DE ESTOQUE}

O controle do estoque precisa de processos para mantê-lo e organizá-lo. Com essas características básicas citadas pelo autor Ching (2012), referentes à processos de custos fixos destinados à manutenção do estoque; burocracia nas aquisições requeridas para reposição do estoque; e previsões de incertezas, pois nos processos de aquisições de materiais o estoque está sujeito à riscos na transição do fornecedor até o cliente; diversas situações podem se tornar presentes e causar diversos danos para a organização.

Para Bowersox (2014), gerenciar um estoque envolve vários riscos que dependem da posição da empresa no canal de distribuição. As aferições típicas que podem comprometer o estoque são: duração, intensidade e extensão. A administração é importantíssima para entender essas relações para estabelecer diretrizes de estoque em relação a quando e quanto pedir, sendo os principais indicadores de desempenho o nível de serviços e o estoque médio.

\subsection{PLANEJAMENTO ESTRATÉGICO}

Em concordância com Dalcorso (2012), o planejamento estratégico é uma ferramenta de desenvolvimento gerencial, composta por diversas etapas até que se possa elaborar o planejamento. Faz-se fundamental que outras ferramentas sejam executadas de forma correta para que, através da obtenção de todos os dados necessários, se tenha uma boa visão da situação atual da empresa, sendo possível a elaboração de estratégias que visam o crescimento do desempenho segundo o plano de ação para o cumprimento de metas, sejam elas financeiras ou operacionais. 
Segundo Anthony e Govindarajan (2010), o planejamento estratégico é o processo de tomada de decisão sobre diferentes atividades que serão realizadas ao implementar as estratégias de uma empresa. Eles apontam que o planejamento estratégico e a preparação do orçamento incluem o planejamento, mas os tipos de atividades propostas nestes são diferentes em ambos os processos.

Andrade (2020) afirma que o planejamento mostra o caminho da organização ao alcance de seus objetivos de desempenho de curto e longo prazo com mudanças competitivas e abordagens de ação para obtenção de resultados programados. Além de que, a implementação de um processo formal de planejamento na sociedade pode trazer muitas vantagens e benefícios, como por exemplo, motivação e comprometimento com autoconhecimento adjunto a organização e garantir à mesma uma gestão ideal.

\subsubsection{ORÇAMENTO}

Segundo Carneiro (2015), o orçamento empresarial é a projeção de receitas e gastos que uma organização elabora dentro de um determinado período de tempo. Feltrin e Buesa (2013) afirmam que o orçamento empresarial funciona como um diferencial para a coordenação das receitas e despesas do setor administrativo, gerando melhoria dos resultados.

\subsubsection{FLUXO DE CAIXA}

Fleuriet e Zeidan (2015), formulam que o fluxo de caixa é um instrumento crucial para uma boa gestão financeira. Trata-se do produto final da projeção de todos os registros de entradas e saídas efetuados. Assim, quando são contraídas, estas são pagas; e quando são pagas, estas são registradas diária, semanal e mensalmente, permitindo saber quanto uma organização pode gastar, o quanto se pode investir, se o desempenho é satisfatório, entre outras informações.

RC: 101629

Disponível em:

https://www.nucleodoconhecimento.com.br/contabilidade/contabilidade-gerencialaplicadas 


\subsubsection{PRECIFICAÇÃO DE PRODUTOS COMERCIALIZADOS}

É fundamental a estratégia de precificação para o bom desempenho das empresas no mercado, ela condiciona o faturamento. De acordo com César (2009) o "preço é um valor arbitrado para um bem ou serviço e qualquer transação de negócio envolve um valor monetário que é a precificação."

Segundo Alves (2013), a formação do preço de venda sofre influência dos custos envolvidos na produção e ou aquisição dos bens e serviços comercializados pelas empresas. Da mesma forma, as despesas comerciais, administrativas e financeiras não podem jamais ser desconsideradas.

\subsection{FERRAMENTAS DA CONTABILIDADE GERENCIAL PARA AS EMPRESAS DE PEQUENO PORTE}

Para Montoto (2012), o principal objetivo da contabilidade gerencial é fornecer informações aos seus usuários para tomada de decisões nos processos de controle e planejamento da entidade, visando sempre estar um passo à frente dos acontecimentos que podem ocasionar crises financeiras, utilizando técnicas como a de captação de informações para o registro de dados nos documentos contábeis com intuito de elaborar relatórios (demonstrações financeiras), indicando com detalhes e exatidão os acontecimentos.

De acordo com Berbel (2017), o resultado do processo de avanço do conhecimento e dos segmentos produtivos da sociedade em todo o mundo originam novas oportunidades empreendedoras em todos os setores, criando a necessidade de desenvolver novos mecanismos de controle, mensuração e informações para avaliação de desempenho e tomada de decisões.

Para Rocha et al. (2014), a contabilidade gerencial utiliza as ferramentas para auxiliar as empresas no melhor desempenho do seu negócio, sendo elas: orçamento, ponto de equilíbrio e fluxo de caixa.

RC: 101629

Disponível em:

https://www.nucleodoconhecimento.com.br/contabilidade/contabilidade-gerencialaplicadas 
Segundo Wander (2020), a contabilidade gerencial preocupa-se com o processo de identificação, mensuração, acumulação, análise, preparação, interpretação e comunicação de informações financeiras utilizadas pela administração. É importante frisar que a qualidade das informações tem mais relevância do que a quantidade (LIMA, 2019).

Portanto, os gestores precisam propor alternativas viáveis, certificando-se de que as suas decisões tomadas correspondem ao problema evidenciado. As informações colhidas são, efetivamente, àquelas necessárias para a tomada de decisão adequada (BALTZAN e PHILLIPS, 2012).

\subsubsection{CONTROLE DE CUSTOS E DESPESAS}

De acordo com Moura (2013), a despesa se aplica diretamente na diminuição do ativo, por conta da saída do dinheiro, o valor dedicado à despesa não terá retorno financeiro. Sendo assim, as despesas geradas normalmente são devido aos serviços utilizados nas áreas administrativa, comercial e financeira.

Para Wernke (2012), o conceito de despesa é o valor despendido de um grande volume diretamente ligado com bens ou serviços, seja de forma direta ou indireta. Informando como exemplo uma loja, todos os gastos não relacionados à mercadoria vendida, mas sendo importante para o funcionamento diário, são denominadas despesas.

Conforme Souza (2011), de forma mais tradicional, entende-se que despesa é todo valor de bens e serviços não ligados diretamente com o processo de produção de outros produtos, bens ou serviços.

Conforme Nonato (2014), os custos estão diretamente ligados ao processo de produção de um bem ou serviço, tendo objetivo de trazer benefícios atuais ou futuros para instituição, após a finalização ou venda do insumo ou serviço. Com isso, todo custo tem um retorno financeiro.

RC: 101629

Disponível em:

https://www.nucleodoconhecimento.com.br/contabilidade/contabilidade-gerencialaplicadas 


\subsubsection{GESTÃO DE ESTOQUES}

Para Grant (2012), a melhor forma de administrar o estoque é por meio de três classificações, sendo elas: informais, estatísticos e demanda independente. Referindo-se à demanda de um produto que é independente pode-se citar, por exemplo, produtos de saúde e beleza. Já o método informal age por meio de análise $A B C$, que são organizadas por categorias dependendo da sua importância para as vendas. $\mathrm{E}$ os métodos estatísticos se baseiam em três pontos: por meio de revisão contínua ou quantidade de pedido de compra, reavaliação periódica e métodos que alternam entre os dois citados anteriormente.

Conforme Closs (2014), o objetivo de uma boa gestão no estoque é alcançar o desejado serviço proposto ao cliente com o mínimo de comprometimento de estoque. As estratégias levantadas devem ser elaboradas para manter o menor investimento financeiro possível, tendo como objetivo principal conseguir girar ao máximo o estoque, satisfazendo, ao mesmo tempo, as necessidades de serviços.

De acordo com Corrêa (2014), para uma melhor gestão dos processos produtivos do estoque, é necessário utilizar as técnicas do ERPs, que é um sistema empregado para auxiliar e coordenar o suprimento e o consumo dos produtos de estoque em cadeias de suprimento, cujo atua com base nos dados e calcula planos de produção futura, falta de materiais, quando e quanto produzir e comprar.

Para Meindl (2012), o estoque tem participação crucial na estratégia competitiva da empresa, podendo ser utilizado para alcançar essa expansividade, disponibilizando uma grande quantidade de estoque aos clientes. Contrariamente, o estoque também pode ser usado para uma eficiência maior, reduzindo, com isso, a utilização de armazenagem centralizada.

RC: 101629

Disponível em:

https://www.nucleodoconhecimento.com.br/contabilidade/contabilidade-gerencialaplicadas 


\subsubsection{MÉTODOS DE CONTROLES DE ESTOQUES UTILIZADOS NAS EMPRESAS}

Segundo Schier (2011), os métodos de avaliação de estoque mais utilizados no Brasil são: PEPS ou FIFO (primeiro a entrar, primeiro a sair); UEPS (último a entrar, primeiro a sair); custo médio ponderado (ou média ponderada móvel - MPM); custo específico; e método do varejo.

Dentre estes cinco métodos, Schier (2011) sustenta que os únicos que são aceitos pelo Fisco (Receita Federal e seus fiscais) são o PEPS, UEPS e o MPM, pelo fato destes serem os únicos que proporcionam uma base de cálculo para IR, sendo que o presente artigo tem como foco estes três métodos.

\subsubsection{PEPS}

PEPS ou FIFO significa "primeiro que entra, primeiro que sai", traduzida do inglês First In, First Out. "Refere-se ao critério de considerar o CMV como correspondente ao Custo da Mercadoria mais antiga remanescente no estoque" (MARION, 2009). PEPS é o método de controle de estoque mais usado e recomendado para organizações comerciais, visto que suas vantagens são ideais para esse ramo de atuação, como combate a perda e vencimento de mercadoria, mostrando um real valor do preço de custo de cada produto, uma vez que esse cálculo é feito baseado nas primeiras compras.

\subsubsection{UEPS}

UEPS ou LIFO significa "último que entra, primeiro que sai", traduzida do inglês Last In, First Out. Está ligado ao princípio do Conservadorismo ou princípio da Prudência, onde é adotado um menor valor para o ativo. Para organizações do ramo de atividade comercial esse método não é recomendável, tendo em vista que suas características são contrárias a ideia de rotatividade alta de estoque, uma das

RC: 101629

Disponível em:

https://www.nucleodoconhecimento.com.br/contabilidade/contabilidade-gerencialaplicadas 
principais características para se ter uma boa gestão de estoques. Esse critério tornou-se ilegal na legislação brasileira. "Refere-se ao critério de considerar o CMV como o correspondente ao Custo de Compra da Mercadoria mais recente remanescente no estoque" (MARION, 2009).

\subsubsection{CUSTO MÉDIO}

Média Ponderada e PEPS são os únicos métodos aceitos pelo Ministério da Fazenda e pela legislação do Imposto de Renda. É baseado na cronologia das entradas e saídas. "O procedimento de baixa dos itens de estoque é feito normalmente pela quantidade da própria ordem de produção e os valores finais de saldo são dados pelo preço médio dos produtos" (MARTINS e ALT, 2009).

\section{MATERIAIS E MÉTODOS}

A metodologia é a forma pela qual a pesquisa foi realizada, descrevendo o seu contexto e o respectivo tamanho da amostra estudada, bem como a forma de coleta e análise dos resultados.

Segundo Zanella (2013, p.23), a metodologia é o conjunto de regras de como fazer a pesquisa, a fim de que a sua compreensão seja dada de forma clara e objetiva.

Deste modo, o trabalho usufrui da contabilidade e suas ferramentas para buscar métodos e formas que ajudarão a descobrir a solução dos processos para mostrar o melhor caminho para tomada de decisão, isto é, organizando, relatando e se adequando ao cenário atual.

\subsection{PROCEDIMENTOS METODOLÓGICOS}

Para Bervian e Cervo (2006) são os métodos e as ordens que se deve impor aos diferentes processos necessários para atingir um certo fim ou um resultado desejado

RC: 101629

Disponível em:

https://www.nucleodoconhecimento.com.br/contabilidade/contabilidade-gerencialaplicadas 
através de um conjunto de processos empregados na investigação e nas demonstrações da verdade.

Aragão e neta (2017) definem que os procedimentos metodológicos são como etapas dispostas ordenadamente para investigação da verdade, fazendo o estudo de uma ciência para atingir uma determinada finalidade.

Esta pesquisa foi realizada por meio de coleta de informações encontradas em noticiários, revistas, jornais e conversas informais, tendo como objetivo elucidar o tema, baseando-se em fatos e relatórios de dentro das empresas e utilizando ferramentas da contabilidade para tais relatórios com o propósito de ajudar na manutenção da rotatividade do estoque.

\subsubsection{MÉTODOS DE PESQUISA}

Segundo Santos (2012), a pesquisa bibliográfica é necessária para quaisquer tipos de trabalho acadêmico científico, tais como: tese, dissertação, monografia, artigo, comunicação, resenha ou ensaio científico, utilizando as técnicas de utilização de fichários, documentos escritos, publicações técnicas, livros, revistas, boletins, folhetins anais e anuários.

Neste trabalho, utilizou-se a pesquisa bibliográfica para extração de informações direcionadas à fundamentação do estudo, analisando criticamente as descobertas de novos fatos, dados, relações ou leis para expandir o campo de conhecimento. Os dados obtidos de forma qualitativa também foram analisados com o intuito de esclarecer a situação em que a empresa se encontra, com o objetivo de orientar os responsáveis com mais clareza levando em consideração o momento pandêmico atual. Ou seja, fazer com que setor gerencial tenha uma melhor interpretação do cenário atual, levando em conta as diretrizes governamentais e o departamento pessoal com o intuito de analisar os dados relacionando a realidade atual com a prática da empresa. 


\subsubsection{NATUREZA DE PESQUISA}

De acordo com a linha de raciocínio de Marconi e Lakatos (2011), a pesquisa adota procedimentos formais juntamente com métodos de pensamentos reflexivos e se constitui no caminho para se conhecer a realidade ou para descobrir verdades parciais.

Segundo Andrade (2010), quanto à natureza, a pesquisa pode constituir-se em um trabalho ou em um resumo que venha contribuir com novas conquistas e descobertas para a evolução do conhecimento científico.

Ressalta-se quanto à natureza de pesquisa, que esta corresponde à pesquisa aplicada, pois apontam-se as descobertas na prática da empresa.

\subsubsection{DO PONTO DE VISTA DA PESQUISA}

Apresenta-se a pesquisa com o objetivo de estudar os acontecimentos para investigar com características holísticas os eventos que levantaram algumas informações vindas de noticiários, momentos vivenciados e conversas informais com gestores e gerentes de empresas, com o intuito de obter as primeiras informações de como e por que tais decisões foram tomadas para obter dados para elaboração do mapeamento de tomada de decisões dentro da organização.

\section{CONSIDERAÇÕES FINAIS}

Esta pesquisa surgiu a partir dos acontecimentos da crise econômica da covid-19, que afetou financeiramente e economicamente muitos negócios comerciais, na qual as empresas de pequeno porte foram os segmentos mais afetados, muitas por falta de planejamento e estratégias para lidar em situações perante os acontecimentos adversos.

RC: 101629

Disponível em:

https://www.nucleodoconhecimento.com.br/contabilidade/contabilidade-gerencialaplicadas 
Em resposta à pergunta problema abordada na pesquisa: Quais ferramentas da contabilidade gerencial podem trazer resultados satisfatórios para essas empresas? Entende-se que o estudo responde o problema de pesquisa considerando que discorre sobre as ferramentas da contabilidade gerencial aplicadas aos estoques de materiais para tomada de decisão das empresas comerciais de pequeno porte em meio à crise econômica da pandemia covid-19. Posto as ferramentas da contabilidade gerencial adequadas para esse tipo de negócio, acredita-se que para manter a gestão e o controle dos estoques é necessário o uso de planejamento estratégico, orçamentos, controle de fluxo de caixa, precificação de produtos, controle de custos e despesas, métodos de controle PEPS, UEPS e custo médio.

Os objetivos da pesquisa também foram atendidos. Através desta pesquisa, foram apresentados ferramentas e conceitos importantes para utilização da contabilidade gerencial; gerou-se conhecimento sobre como manter um estoque preparado para futuras complicações; e estudou-se a contabilidade gerencial como uma ferramenta que conduz na transformação de tomada de decisões, valores estes que aumentam a saúde da empresa e ajuda na progressão das atividades organizacionais.

Analisou-se também que a contabilidade gerencial voltada para a tomada de decisão é indispensável para qualquer empreendimento, seja ele pequeno, médio ou grande. As ferramentas utilizadas e as informações geradas pela contabilidade conduzem a empresa ao sucesso ou fracasso.

Assim, sobre o aspecto da utilização das informações da contabilidade gerencial, pode-se dizer que reduzirá os riscos financeiros, dando segurança maior à empresa nas tomadas de decisões, preparadas e fundamentadas que serão essenciais em situações emergenciais e cotidianas.

O estudo do tema foi realizado a partir da pesquisa bibliográfica, através de livros técnicos e metodológicos, artigos científicos e sites, que trouxeram os resultados esperados. 
Este trabalho não se restringe somente à crise econômica da pandemia, podendo abrir várias possibilidades de pesquisa futuras. Portanto, recomenda-se que sejam aplicados modelos semelhantes na intenção de obter resultados, com a finalidade de aperfeiçoá-lo, criando fontes sólidas de pesquisa e aplicação.

\section{REFERÊNCIAS}

ALVES, R. Contabilidade gerencial: livro-texto com exemplos, estudos de caso e atividades práticas. 1. ed. Brasil: Atlas, 2013.

ANDRADE. Cadernos de Saúde. SciELO Public Health, 2020.

ANTHONY, R. N.; GOVINDARAJAN, V. Sistemas de controle gerencial. 12. ed. São Paulo: McGraw-Hill, 2010

ATRILL, P.; MCLANEY, E. Contabilidade gerencial para tomada de decisão. 1. ed. São Paulo: Saraiva, 2014.

BERBEL, J. Introdução à Contabilidade e Análise de Custos. São Caetano do Sul: Editora STS, 2017.

BOWERSOX, D. Gestão de logística da cadeia de suprimentos. 4. ed. São Paulo: AMGH, 2014.

BRASIL. Lei complementar no 123, de 14 de dezembro de 2006. Brasília: Diário Oficial da União, 2006.

CHING, H. Y. Gestão de estoque na cadeia de logística integrada. 4. ed. São Paulo: Atlas, 2010.

CRAVEIRO, A. Fluxo de caixa na prática. Administradores.com, 2017. Disponível em: https://administradores.com.br/artigos/fluxo-de-caixa-na-pratica. Acesso: 16 de ago. de 2021.

RC: 101629

Disponível em:

https://www.nucleodoconhecimento.com.br/contabilidade/contabilidade-gerencialaplicadas 
DALCORSO, C. Z. O planejamento estratégico: um instrumento para o gestor de escola pública. Jundiaí: Paco Editorial, 2012.

DORION, E. Reflexão sobre os impactos da pandemia covid-19 no setor de serviço e comércio e as perspectivas de retomada e mudanças para sociedade. Santa Maria: Universidade Federal de Santa Maria, 2021. Disponível em: https://www.ufsm.br/app/uploads/sites/820/2021/03/Textos-para-Discussao-25Reflexao-sobre-os-impactos-da-pandemia-COVID-19-no-setor-de-Servicos-eComercio.pdf. Acesso em: 15 de ago. de 2021.

FELTRIN, D.; BUESA, N. Revista Eletrônica Gestão e Negócios. FAC São Roque, 2012.

FLEURIET, M.; ZEIDAN, R. O Modelo Dinâmico de Gestão Financeira. 1. ed. Brasil: Alta Books, 2015.

GARRISON, R. H. Contabilidade Gerencial. 14. ed. Porto Alegre: 2013.

GRANT, D. Gestão de logística e cadeia de suprimentos. São Paulo: Saraiva, 2012.

https://www.lume.ufrgs.br/bitstream/handle/10183/225378/001126867.pdf?sequ ence=1. Acesso em: 15 de ago. de 2021 .

IUDÍCIBUS, S. de. Teoria da Contabilidade. 11. ed. São Paulo: Atlas, 2015.

LIRA, M. C.; ALMEIDA, S. A. de S. A volatilidade no mercado em tempos de pandemia do (novo) coronavírus e da covid-19: impactos e projeções. Araguaina: JNT - Business and technology journal, 2020. Disponível em: http://revistas.faculdadefacit.edu.br/index.php/JNT/article/download/677/499. Acesso em: 15 de ago. de 2021.

LUIZ, H. Administração de cadeias de suprimento e logística. São Paulo: Atlas, 2014.

RC: 101629

Disponível em:

https://www.nucleodoconhecimento.com.br/contabilidade/contabilidade-gerencialaplicadas 
MARION, J. C. Contabilidade Empresarial. 15. ed. São Paulo: Atlas, 2009.

MARTINS, P. G.; ALT, P. R. C. Administração de Materiais e Recursos Patrimoniais. São Paulo: Saraiva, 2009.

MATTEI, L.; HEINEN, V. L. Impactos da crise da covid-19 no mercado de trabalho brasileiro. Brazilian Journal of Political Economy, 2020. Disponível em: https://www.scielo.br/j/rep/a/8snSbBwVqmYgd5pZVQ5Vhkn/?lang=pt\#. Acesso em: 16 de ago. de 2021.

MEINDL, P. Gestão de cadeia de suprimentos: estratégia, planejamento e operações. 4 ed. São Paulo: Pearson, 2012.

MENDES, S. A importância da contabilidade como instrumento de gestão nas empresas: uma análise dos impactos do coronavírus nas micro e pequenas empresas na cidade de João Pessoa/PB. João Pessoa: Universidade Federal da Paraíba. 2020.

https://repositorio.ufpb.br/jspui/bitstream/123456789/18006/4/SDM08092020.pdf. Acesso em: 15 de ago. de 2021.

MENEZES, A.; et al. Metodologia científica: teoria e aplicação na educação a distância. Petrolina - PE. Universidade federal do vale do São Francisco 2019. Metodologia do trabalho científico. São Paulo: editora Atlas, 2011.

MONTOTO, E. Contabilidade geral esquematizado. São Paulo: Editora Saraiva, 2012.

PEREIRA, M. F. Administração Estratégica. Florianópolis: departamento de administração estratégica/UFSC, 2011. Disponível em: http://www.ead.uepb.edu.br/arquivos/licitacao_livros_admpub/16administra\%E7\%E3 \%\%20estrat\%E9gica/livro_grafica\%20administra\%E7\%E30\%20estrat\%E9gica.pdf. Acesso em: 30 de set. de 2021. 
RIBEIRO, O. Contabilidade comercial fácil. 16. ed. ampl. e atual. São Paulo: Saraiva, 2009.

ROCHA, J. F. de A. et al. A contabilidade gerencial no processo de tomada de decisão e o conhecimento das empresas sobre sua importância. Revista Fatec Zona Sul, São Paulo, $2018 . \quad$ Disponível em: $<$ http//www.revistarefas.com.br/index.php/RevFATECZS/article/download/231/192>. Acesso em: 16 de ago. de 2021.

SCHIER, C. U. da C. Gestão de custos. 2 ed. Curitiba, PR: Ibpex, 2011.

SEBRAE. Micro e pequenas empresas geram 27\% do PIB do Brasil. SEBRAE, 2021. Disponível em: https://www.sebrae.com.br/sites/PortalSebrae/ufs/mt/noticias/microepequenas-empresas-geram-27-do-pib-

do brasilad0fc70646467410VgnVCM2000003c74010aRCRD. Acesso em: 31 de ago. de 2021.

SEBRAE. Participação das Micro e Pequenas Empresas na Economia Brasileira. Brasília, 2014.

TAGLIANI, C. O impacto da pandemia covid-19 na situação econômicofinanceira de uma microempresa. Universidade Federal do Rio Grande do Sul. Porto Alegre, 2020.

ZANELLA, L. C. H. Metodologia de pesquisa. 2. ed. Florianópolis: Departamento de Ciências da Administração/ UFSC, 2013.

Enviado: Outubro, 2021.

Aprovado: Novembro, 2021.

RC: 101629

Disponível em:

https://www.nucleodoconhecimento.com.br/contabilidade/contabilidade-gerencialaplicadas 